\title{
Medical management of recurrent endometrioma with long-term norethindrone acetate
}

\author{
This article was published in the following Dove Press journal: \\ International Journal of Women's Health \\ 29 March 2012 \\ Number of times this article has been viewed
}

\author{
Ozgul Muneyyirci-Delale ${ }^{1,2}$ \\ Jenny Anopa' \\ Cassandra Charles' \\ Deepali Mathur' \\ Rudolph Parris' \\ Jed B Cutler ${ }^{2}$ \\ Ghadir Salame ${ }^{1,2}$ \\ Ovadia Abulafia ${ }^{1,2}$ \\ 'Department of Obstetrics and \\ Gynecology, SUNY Downstate \\ Medical Center, New York, NY, USA; \\ ${ }^{2}$ Department of Obstetrics and \\ Gynecology, Kings County Hospital \\ Center, New York, NY, USA
}

\begin{abstract}
Purpose: Evaluate the efficacy of norethindrone acetate in the resolution of symptoms and regression of recurrent endometrioma.

Patients and methods: Retrospective chart review at SUNY Downstate Medical Center of patients with a history of surgical excision of endometrioma (with histological confirmation) and recurrent endometrioma (demonstrated by strict sonographic criterion of endometrioma) who were willing to undergo follow-up. Patients were prescribed norethindrone acetate to be taken daily with follow-up sonograms until cysts regressed. Statistical analysis included Student's $t$-test and a simple linear regression model to assess cyst regression over time during treatment.

Results: Degree of pain was significantly lower on treatment when compared to baseline $(P<0.00001)$. Cyst size was significantly smaller in as little as 3 months $(P<0.0001)$. Average rate of regression with continuous treatment was $0.025 \pm 0.015 \mathrm{~cm} /$ day. Total mean \pm standard deviation regression time is $10.28 \pm 8.25$ months.

Conclusion: Norethindrone acetate was effective in eradicating symptoms and producing complete regression of recurrent endometriomas. It should be considered for patients who are likely to adhere to a prolonged treatment regimen and comply with recommendations for surveillance with serial sonograms.
\end{abstract}

Keywords: endometriosis, regression, dysmenorrhea, medical therapy

\section{Introduction}

Endometriosis is one of the most challenging gynecological disorders of our era ${ }^{1}$ that occurs in women of reproductive age. According to the National Institute of Health, approximately 5.5 million women in North America have endometriosis. ${ }^{2}$ It is found in 2\%-22\% of asymptomatic women, ${ }^{3-6} 40 \%-60 \%$ of patients with dysmenorrhea, and in $20 \%-30 \%$ of women with primary infertility. ${ }^{7,8} \mathrm{~A}$ common form of endometriosis is an ovarian endometrioma, occurring in $17 \%-44 \%$ of women who have endometriosis. $4,7,12,13$ Norethindrone acetate (NA) has been established as an effective long-term treatment for endometriosis because it produces a hypoestrogenic, acyclic hormonal environment by suppressing gonadotropins, inhibiting ovulation, and developing amenorrhea with eventual decidualization and atrophy of endometrial tissue..$^{9-11}$

A recurring endometriotic ovarian cyst is often of concern and frequently a cause of repeated surgical and medical intervention. Laparoscopic resection has been proposed as the gold standard of treatment for endometriomas and related symptoms. ${ }^{14-18}$ However, there is a relatively high recurrence rate of endometriomas $(12 \%-30 \%$ after 2-5 years of follow-up), ${ }^{19-25}$ which were treated primarily with conservative surgical management. ${ }^{26}$ This rate may be underestimated as it does not take into account patients
Correspondence: Ozgul Muneyyirci-Delale Associate Professor, Director, Division of Reproductive Endocrinology and Infertility, SUNY Downstate Medical Center, 450 Clarkson Avenue, Box \# 24, Brooklyn, New York, NY I I 203, USA

$\mathrm{Tel}+\mathrm{l} 7182702101$

$\mathrm{Fax}+\mathrm{I} 7182702067$

Email ozgul.muneyyirci-delale@

downstate.edu 
who have recurrent cysts but are asymptomatic and do not seek further testing or treatment. Furthermore, few studies have shown the effect of pure medical therapy on endometriomas and some have found that medical treatment alone is inadequate. ${ }^{27,28}$ Specifically, Donnez et al suggested that endometriomas equal to or larger than $3 \mathrm{~cm}$ do not respond well to medical therapy. ${ }^{29}$

The management of recurrent endometriomas and the efficacy of a second surgery and its associated symptoms have only been explored in a few studies. ${ }^{23,30-33}$ Efforts to surgically extirpate this lesion and preserve ovarian function have had mixed results. Laparoscopic techniques for the excision of endometrioma, in particular the stripping technique, have been controversial because they may result in excessive loss of normal ovarian tissue. ${ }^{26}$ Recent studies have suggested that the stripping of endometrioma may induce loss of follicle reserves and may decrease the number of oocytes retrieved during in vitro fertilization cycles. ${ }^{18,19,23,26}$ These findings suggest that the surgical removal of a recurrent endometrioma is best avoided if preservation of ovarian function is paramount. ${ }^{26}$ Supporting this view is data published showing an elevated risk for premature ovarian failure following resection of bilateral endometriomas. ${ }^{34,35}$ Additionally, when endometriomas recur, they present an even greater surgical challenge due to the formation of postsurgical adhesions in conjunction with the underlying intense chronic inflammatory process associated with endometriosis. Despite the general dissatisfaction with surgical treatment for endometriomas, few studies have examined the efficacy of medical therapy in this clinical context. ${ }^{14,31}$ In support of the theory that progesterone therapy may reduce recurrence rates are studies which show that pregnancy, a condition characterized by tonic elevations of serum progesterone, is protective in patients with prior resection of endometriomas. ${ }^{24}$

Studies examining the efficacy of medical therapy for recurrent endometriomas have thus far evaluated gonadotropin-releasing hormone ( $\mathrm{GnRH}$ ) agonists, danazol, aromatase inhibitors, and oral contraceptive pills. ${ }^{25,28,36-40}$ However, all of these studies, with the exception of Seal et $\mathrm{al}^{36}$ have solely focused on preventing, rather than treating, a recurrence. Seal et $\mathrm{al}^{36}$ showed the effect of aromatase inhibitors on treating recurrent endometriomas. However, a major limitation was that the authors evaluated the effectiveness of aromatase inhibitors in only five subjects.

To our knowledge, no studies have been conducted that evaluate the efficacy of NA in effecting resolution of symptoms and regression of recurrent endometriomas. In this retrospective review we aim to evaluate NA in achieving these clinical outcomes.

\section{Material and methods}

A retrospective chart review was conducted at Downstate Medical Center's Reproductive Endocrinology and Infertility Clinic with approval from the Institutional Review Board. Women that underwent laparotomy or laparoscopic removal of ovarian endometrioma, had symptomatic endometriomas (defined by the presence of pelvic pain and abnormal bleeding), and were taking NA were included in this review. The presence of a recurrent endometrioma (unilateral or bilateral) was defined as the sonographic evidence of a round, homogenous, hypoechoic, low-level echo cyst, or thin internal heterogenous trabeculation (with or without internal septa), absence of, or poor vascularity of capsule, and septa. ${ }^{41}$ Women who had adnexal masses with solid components and/or desired immediate childbearing were excluded from this review. Twenty-one patients met our inclusion criteria.

All patients were initially prescribed $5 \mathrm{mg}$ of NA. The dose was increased by $2.5 \mathrm{mg}$ according to the patient's response until amenorrhea was achieved. A pelvic sonogram was performed prior to starting treatment and all participants were re-evaluated at 3 month intervals. Clinical and demographic data including age, parity, weight, symptoms, medical treatment compliance, and sonogram findings were recorded. Dysmenorrhea was evaluated by visual analog scale (VAS), with 0 representing no pain and 10 representing the worst imaginable pain. The following parameters were retrospectively analyzed in follow-up visits: dysmenorrhea by VAS, presence of breakthrough bleeding, weight changes, and serial pelvic sonograms for endometrioma cyst dimensions. A simple linear regression model was constructed to assess cyst regression over time during treatment. Resistant methods were utilized to fit the models.

\section{Results}

Twenty-one patients met our inclusion criteria. However, three patients (P1, P2, P3) were excluded from analysis. $\mathrm{P} 1$ had high follicle-stimulating hormone and luteinizing hormone levels. Thus, the decrease in endometrioma size may have been attributable to menopause. P2 and P3 had questionable compliance due to frequent and long international travel between visits and sonograms. Additionally, their dosage schedule differed from all other patients in this review. However, all three of these patients had significant cyst regression while on NA. 


\section{Demographics}

Eighteen patients were assessed in this review. The patient characteristics and demographics are summarized in Table 1. Comprising the 18 patients, twelve underwent a laparoscopy while six had a laparotomy and 14 patients had a unilateral endometrioma while four had bilateral endometriomas. We compared subjects on surgery type, endometrioma location, and age and examined their effect on response rate between the two groups (completed versus on treatment) and found no significant effect.

\section{Pain}

Pain scores were rated using VAS where 10 represents the worst imaginable pain. Sixteen $(88.89 \%)$ of patients reported complete resolution (100\%) of dysmenorrhea on treatment, with two $(11.11 \%)$ patients only experiencing mild discomfort (a pain grade of 3 or lower) at their last visit. The clinical outcomes for pain (Figure 1) in our patient population are presented in quartiles. Length of treatment ranged from just under 3 months to 33 months and thus quartile scores were retrospectively composed based on the individual patient's length of treatment. The averages across all subjects for each quartile are reported. All subjects had a baseline and final score. Two subjects had two missing values and one subject had three missing values due to a treatment time ranging from less than 3 months to 6 months and thus requiring fewer intermediary visits. One additional subject had two missing values due to having only three visits in her 1-year treatment length. These missing values were dropped and not included in the averages. The degree of pain was found to be significantly lower at all intervals when compared to baseline $(P<0.00001)$.

\section{Cyst size}

A simple linear regression model was constructed to assess cyst regression over time during treatment. Resistant methods were utilized to fit the models. Fourteen patients had complete regression and four patients are currently receiving treatment. For patients currently on treatment, their regression rates were projected into the future based upon their current rate of regression from previous visits. Total across both groups, baseline cyst size for all patients was $6.46 \pm 3.92 \mathrm{~cm}$ and the average dose was $5 \mathrm{mg}$ of NA taken orally at bedtime. The average rate of regression (mean \pm $\mathrm{SD})$ with continuous treatment was $0.025 \pm 0.015 \mathrm{~cm} /$ day and average length of treatment was $10.28 \pm 8.25$ months. Individuals currently on treatment had significantly higher cyst size $(11.23 \mathrm{~cm} \pm 5.92 \mathrm{~cm}$ vs $4.47 \mathrm{~cm} \pm 1.90 \mathrm{~cm}$; $P=0.0013$ ) thus resulting in significantly more months necessary for complete regression $(20.01 \pm 10.66$ vs 7.47 $\pm 4.52 ; P=0.0012)$. The rate of regression did not differ between the two groups. Figure 2 shows the average trend of cyst regression across 3 month intervals. Using Student's $t$-test, all intervals were significantly lower compared to baseline $(P<0.0001)$.

\section{Side effects}

A frequent side effect of NA is breakthrough bleeding. Breakthrough bleeding was reported by eight (44.44\%) of

Table I Patient demographics (mean \pm standard deviation) by completion status $(n=18)$

\begin{tabular}{|c|c|c|c|}
\hline & Complete & Incomplete & $P$-value ${ }^{a}$ \\
\hline Age (years) & $35.1 \pm 8.6$ & $35.2 \pm 8.5$ & Ns \\
\hline Age at menarche (years) & $12.9 \pm 1.4$ & $13.3 \pm 1.7$ & Ns \\
\hline Weight (kg) & $76.9 \pm 22.22$ & $76.5 \pm 22.1$ & Ns \\
\hline Treatment time (months) & $7.5 \pm 7.5$ & $20.1 \pm 10.66$ & 0.0012 \\
\hline Maximum cyst size $(\mathrm{cm})$ & $4.47 \pm 1.9$ & $11.23 \pm 5.92$ & 0.0013 \\
\hline Rate of regression (cm/day) & $0.026 \pm 0.017$ & $0.02 \pm 0.011$ & Ns \\
\hline \multicolumn{4}{|l|}{ Endometrioma location } \\
\hline Unilateral & II & 3 & \\
\hline Bilateral & 3 & I & \\
\hline \multicolumn{4}{|l|}{ Type of surgery } \\
\hline Laparoscopy & 11 & $\mathrm{I}$ & \\
\hline Laparotomy & 3 & 3 & \\
\hline \multicolumn{4}{|l|}{ Rate of regression $(\mathrm{cm})$} \\
\hline Unilateral vs bilateral & $0.028 \pm 0.018$ vs $0.021 \pm 0.015$ & $0.02 \pm 0.006$ vs $0.019 \pm 0.0$ & $\mathrm{Ns}^{\mathrm{b}}$ \\
\hline Laparoscopy vs laparotomy & $0.029 \pm 0.02$ vs $0.019 \pm 0.007$ & $0.023 \pm 0.00$ vs $0.018 \pm 0.005$ & \\
\hline Change in weight with treatment $(\mathrm{kg})$ & $2.4 \pm 3.9$ & $0.8 \pm 1.3$ & Ns \\
\hline
\end{tabular}

Notes: aAnalysis performed for all using Student's $t$-test; 'Student's $t$-test and chi-square test. Abbreviation: Ns, Not significant. 


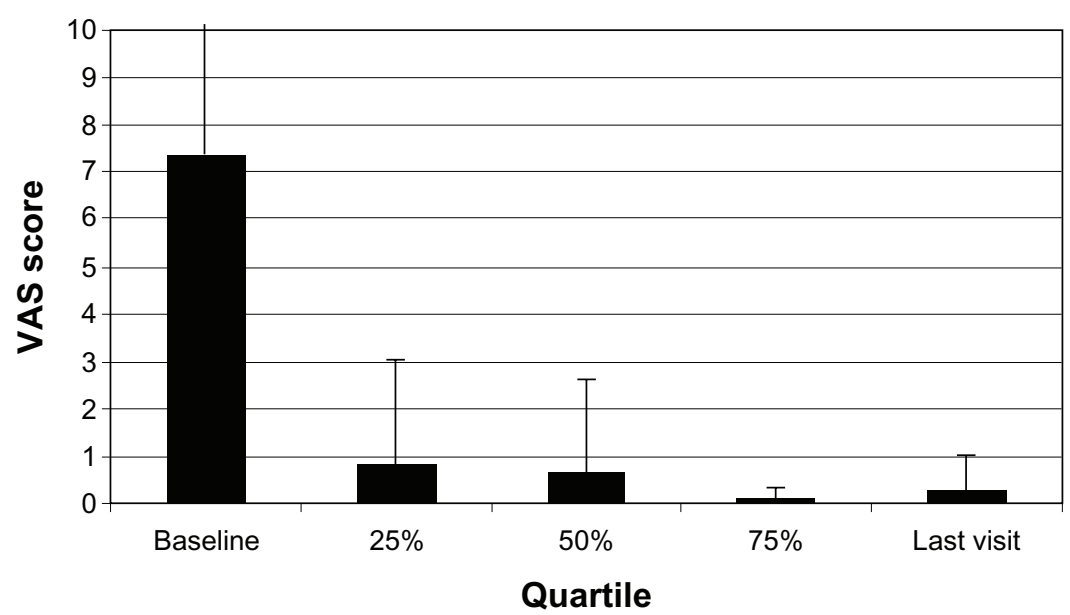

Figure I Pain score (mean \pm standard deviation) was measured by visual analog scale (VAS) from 0-10 with "0" being no pain and "I0" the worst imaginable pain. Note: All intervals were significantly lower when compared to baseline $(P<0.0000 \mathrm{I})$.

18 patients but was tolerated, caused no discontinuations, and was remedied by increasing the dose by $2.5 \mathrm{mg}$ until resolved. Additionally, 15 (83.33\%) of 18 patients reported weight gain (presented in Table 1).

\section{Discussion}

Our most important findings were that long-term therapy with NA for patients with recurrent endometrioma was effective in eradicating symptoms and in producing complete regression of the lesion in individuals that continued treatment. Given that surgical interventions in similar patient populations have had limited success, the medical management described may be a promising noninvasive alternative. The results of our treatment are very promising. There was a significant difference in as little as 3 months for cyst size, bleeding, and pain. All patients had complete resolution of bleeding, and the average pain score was 0.25 at the end of their treatment. Due to this positive effect on pain and bleeding, many of our patients continued treatment in order to prevent another recurrence and avoid surgery at the conclusion of their course.

Studies on the use of GnRH agonists, and oral contraceptive pills for less than 6 months or 12 months, respectively, were found to be ineffective in treating endometriomas..$^{25,38,39}$ Research shows that a 3-month course of a GnRH agonist or danazol had no impact on pelvic pain in women with stage III/IV endometriosis thus requiring a course of 6 months or more. ${ }^{37,39,42}$ Treatment with aromatase inhibitors by Seal et al only reduced pelvic pain from severe (grades 8-10) to moderate (grades 3-4.5) for $80 \%$ of subjects and mild (below grade 3 ) for $20 \%{ }^{36}$

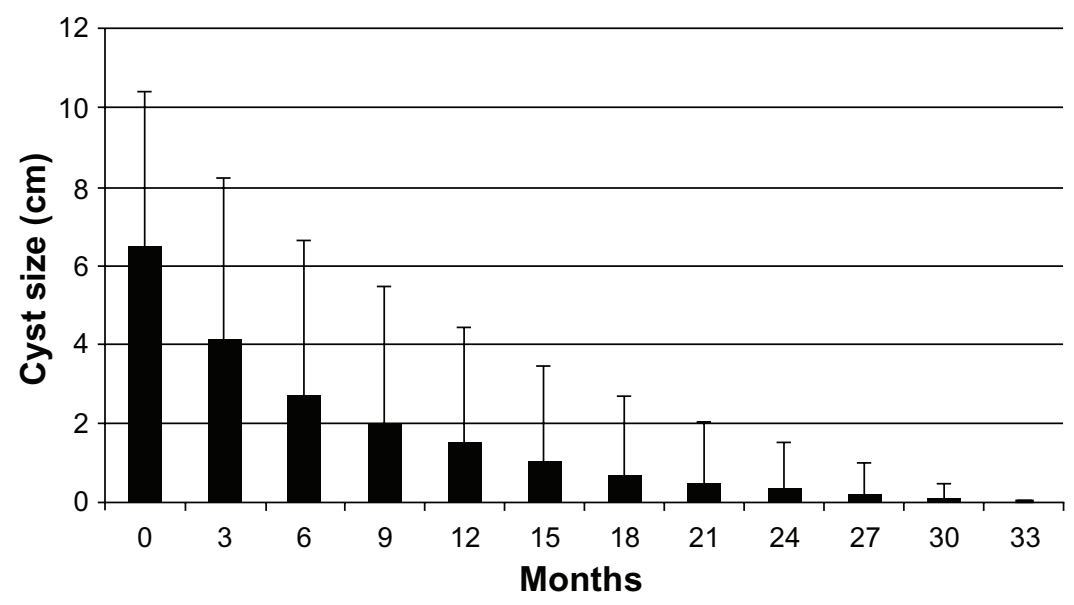

Figure 2 The average cyst size (mean \pm standard deviation) at 3-month intervals.

Note: Student's $t$-test shows that all intervals are significantly smaller compared to baseline $(P<0.000 \mathrm{I})$. 
Our findings showed that NA resulted in significant regression of the cysts and reduction in pain scores from severe to mild for $100 \%$ of our patients in as little as 3 months. Furthermore, subjects from the Seal et al study had taken oral contraceptive pills, calcium, and vitamin $\mathrm{D}$ in order to prevent bone loss. Comparatively, NA is commonly used as add-back therapy, is well tolerated with lesser estrogenic side effects than oral contraceptives, and milder androgenic side effects than danazol. These findings may have implications for patients as they may be relieved of the pain and discomfort in a shorter period of time, and therefore may be an alternative to invasive surgery.

Several strengths of this study warrant mentioning. The histopathologic diagnosis of endometrioma was a criterion for inclusion. As such, all participants in the study shared a definitive diagnosis. This is in contrast to other research where the diagnosis of endometrioma was presumptive as it was based upon imaging studies.

Since the study was designed to evaluate patients treated with noninvasive therapy, the diagnosis of recurrence was predicated upon clinical suspicion and radiologic correlation. Recognizing this potential weakness, strict adherence to the radiologic determinants of recurrent endometrioma was applied in all cases, thereby maximizing the likelihood that the diagnosis in each case was correct.

Finally, all patients were similar demographically.

Some shortcomings of this study are also worth listing. We had a small sample size of 18 patients. However, all of our findings had a $P$-value of $<0.0001$ or better and all subjects had a consistent rate of regression. Secondly, a control group was not included for comparison, so the response to treatment could not be compared to no treatment, and as such, the clinical improvements seen in the women treated may simply be the natural course of the disease rather than therapeutic effect. However, spontaneous regression of endometrioma has not been the clinical course most commonly observed in longitudinal studies. It is unlikely that all, or even most, would have resolved without intervention. As such, in our estimate, the lack of a control group does not significantly invalidate our findings. Additionally, since the majority of patients continued treatment after cyst regression and this study is a retrospective chart review, follow-up recurrence rate could not be evaluated.

There is still no consensus on what is the most appropriate therapy for patients with recurrence of endometrioma. Few studies focus on the management of recurrent endometrioma or the efficacy of surgical management. ${ }^{30,33}$ Those that have done so report suboptimal outcomes in patients who are treated surgically. Despite general dissatisfaction with surgical treatment of endometriomas, only one study has focused on sole medical management for the recurrence of this condition.

Much work remains to be done before a working understanding of recurrent endometrioma is established. Specifically, there are no known risk factors and the natural course of the condition is unknown. As the diagnosis of recurrence is dependent upon the manifestation, and indeed the reporting, of symptoms, the prevalence of the condition is also unknown. Similarly, once the diagnosis of recurrent endometrioma is made, the most effective therapy has not been established. We recommend prospective studies on long-term treatment and follow-up with NA as well as other progestins for comparison.

\section{Conclusion}

Our study supports NA as an effective treatment for this condition. As no gold standard for treatment exists, we recommend treatment with NA as the primary modality with close follow-up for 2 years or until resolution of symptoms is observed. Surgical intervention should be considered only after medical management has failed.

\section{Disclosure}

The authors report no conflicts of interest in this work.

\section{References}

1. Melis GB, Ajossa S, Guerriero S, et al. Epidemiology and diagnosis of endometriosis. Ann N Y Acad Sci. 1994;734:352-357.

2. National Institute of Health, National Institute of Child Health and Human Development. Endometriosis. Available from: http://www.nichd. nih.gov/publications/pubs/endometriosis/. Accessed April 10, 2011.

3. Mahmood TA, Templeton A. Prevalence and genesis of endometriosis. Hum Reprod. 1991;6(4):544-549.

4. Busacca M, Vignali M. Ovarian endometriosis: from pathogenesis to surgical treatment. Curr Opin Obstet Gynecol. 2003;15(4): 321-326.

5. Moen MH, Schei B. Epidemiology of endometriosis in a Norwegian country. Acta Obstet Gynecol Scand. 1997;76(6):559-562.

6. Eskenazi B, Warner ML. Epidemiology of endometriosis. Obstet Gynecol Clin North Am. 1997;24(2):235-258.

7. Ajossa S, Mais V, Guerriero S, et al. The prevalence of endometriosis in premenopausal women undergoing gynecological surgery. Clin Exp Obstet Gynecol. 1994;21(3):195-197.

8. Waller KG, Lindsay P, Curtis P, Shaw RW. The prevalence of endometriosis in women with infertile partners. Eur J Obstet Gynecol Reprod Biol. 1993;48(2):135-139.

9. Muneyyirci-Delale O, Karacan M. Effect of norethindrone acetate in the treatment of symptomatic endometriosis. Intl J Fert Women's Med. 1998;43(1):24-27.

10. Muneyyirci-Delale O, Jalou S. Long-term treatment of symptomatic endometriosis with norethindrone acetate. Clin J Womens Health. 2001;1(2):69. 
11. Muneyyirci-Delale O, Jalou S, Rahman M, Nacharaju V. Can we decrease breakthrough bleeding in patients with endometriosis on norethindrone acetate? Intl J Fertil Womens Med. 2003;48(1):32-36.

12. Jenkins S, Olive DL, Haney AF. Endometriosis: pathogenetics implication of the anatomic distribution. Obstet Gynecol. 1986;67(3): 335-338.

13. Redwine DB. Ovarian endometriosis: a marker for more extensive pelvic and intestinal disease. Fertil Steril. 1999;72(2):310-315.

14. Chapron C, Vercellini P, Barakat H, et al. Management of ovarian endometriomas. Hum Reprod Update. 2002;8(6):591-597.

15. Daniell JF, Kurtz BR, Gurly LD. Laser laproscopic management of large endometriomas. Fertil Steril. 1991;55(4):692-695.

16. Donnez J, Nisolle M, Gillet N, et al. Large ovarian endometriomas. Hum Reprod. 1996;11(3):641-646.

17. Sutton CJ, Ewen SP, Jacobs SA, Whitelaw NL. Laser laproscopic surgery in treatment of ovarian endometriomas. $J$ Am Assoc Gynecol Laprosc. 1997;4(3):319-323.

18. Muzii L, Bellati F, Bianchi A, et al. Laproscopic stripping of endometriomas: a randomized trial on different surgical techniques. Part II: pathological results. Hum Reprod. 2005;20(7):1987-1992.

19. Busacca M, Marana R, Caruana P, et al. Recurrence of ovarian endometrioma after laparoscopic excision. Am J Obstet Gynecol. 1999; 180(3 Pt 1):519-523.

20. Saleh A, Tulandi T. Reoperation after laparoscopic treatment of ovarian endometriomas by excision and by fenestration. Fertil Steril. 1999; 72(2):322-324.

21. Ghezzi F, Beretta P, Franchi M, et al. Recurrence of ovarian endometriosis and anatomical location of the primary lesion. Fertil Steril. 2001;75(1):136-140.

22. Jones KD, Sutton CJ. Recurrence of chocolate cysts after laproscopic ablation. J Am Assoc Gynecol Laprosc. 2002;9(3):315-320.

23. Vercillini P, Chapron C, DeGiorgi O, et al. Coagulation or excision of ovarian endometriomas? Am J Obstet Gynecol. 2003;188(3):606-610.

24. Koga K, Takemura Y, Osuga Y, et al. Recurrence of ovarian endometrioma after laparoscopic excision. Hum Reprod. 2006;21(8): 2171-2174.

25. Vercellini P, Somigliana E, Daguati R, et al. Postoperative oral contraceptive exposure and risk of endometrioma recurrence. Am J Obstet Gynecol. 2008;198(5):504. e1-e5.

26. Exacoustos C, Zupi E, Amadio A, et al. Recurrence of endometriomas after laparoscopic removal: sonographic and clinical follow-up and indication for second surgery. J Minim Invasive Gynecol. 2006; 13(4):281-288.

27. Farquhar C, Sutton C. The evidence for the management of endometriosis. Curr Opin Obstet Gynecol. 1998;10(4):321-332.

28. Jones KD, Fa A, Sutton CJ. The ovarian endometrioma: why it is so poorly managed? Hum Reprod. 2002;17(4):845-849.
29. Donnez J, Smets M, Jadoul P, et al. Laparoscopic management of peritoneal endometriosis, endometriotic cyst and rectovaginal adenomyosis. Ann N Y Acad Sci. 2003;997:274-281.

30. Candiani GB, Fedele L, Verecellni P, et al. Repetitive conservative surgery for recurrence of endometriosis. Obstet Gynecol. 1991;77(3): $421-424$.

31. Jones KD, Sutton CJ. Laproscopic management of ovarian endometriomas: a critical review of current practice. Curr Opin Obstet Gynecol. 2000; 12(4):309-315.

32. Gambone JC, Mittman BS, Munro MG, et al; Chronic Pelvic Pain/ Endometriosis Working Group. Consensus statement for the management of chronic pelvic pain and endometriosis: proceedings of an expert-panel consensus process. Fertil Steril. 2002;78(5):961-972.

33. Fedele L, Bianchi S, Zanconato G, et al. Laparoscopic excision of recurrent endometriomas: long-term outcome and comparison with primary surgery. Fertil Steril. 2006;85(3):694-699.

34. Busacca M, Riparini J, Somigliana E, et al. Postsurgical ovarian failure after laparoscopic excision of bilateral endometriomas. Am J Obstet Gynecol. 2006;195(2):421-425.

35. Reich H, Abrao MS. Post-surgical ovarian failure after laparopscopic excision of bilaterial endometriomas: is this rare problem preventable. Am J Obstet Gynecol. 2006;195(2):421-425.

36. Seal SL, Kamilya G, Mukherji J, De A, Ghosh D, Majhi AK. Aromatase inhibitors in recurrent ovarian endometriomas: report of five cases with literature review. Fertil Steril. 2011;95(1):291. e15-e18.

37. Busacca M, Somigliana E, Bianchi S. Post-operative GnRH analogue treatment after conservative surgery for symptomatic endometriosis stage III-IV: a randomized controlled trial. Hum Reprod. 2001;16(11): 2399-2402.

38. Muzii L, Marana R, Caruana P, et al. Postoperative administration of monophasic combined oral contraceptives after laparoscopic treatment of ovarian endometriomas: a prospective, randomized trial. Am J Obstet Gynecol. 2000;183(3):588-592.

39. Jee BC, Lee JY, Suh CH, et al. Impact of GnRH agonist treatment on recurrence of ovarian endometriomas after conservative laparoscopic surgery. Fertil Steril. 2009;90(1):40-45.

40. Gelbaya TA, Nardo LG. Evidence-based management of endometrioma. Reprod Biomed Online. 2011 Jul;23(1):15-24.

41. Exacoustos C, Zupi E, Carusotti C, et al. Staging of pelvic endometriosis: role of sonographic appearance in determining extension of disease and modulating surgical approach. J Am Assoc Gynecol Laparosc. 2003; 10(3):378-382.

42. Bianchi S, Busacca M, Agnoli B, et al. Effects of 3 month therapy with danazol after laparoscopic surgery for stage III/IV endometriosis: a randomized study. Hum Reprod. 1999;14(5):1335-1337.
International Journal of Women's Health

\section{Publish your work in this journal}

The International Journal of Women's Health is an international, peerreviewed open-access journal publishing original research, reports, reviews and commentaries on all aspects of women's healthcare including gynecology, obstetrics, and breast cancer. Subject areas include: Chronic conditions (migraine headaches, arthritis, osteoporosis);

\section{Dovepress}

Endocrine and autoimmune syndromes; Sexual and reproductive health; Psychological and psychosocial conditions. The manuscript management system is completely online and includes a very quick and fair peer-review system. Visit http://www.dovepress.com/ testimonials.php to read real quotes from published authors. 